\title{
Gingival mask for conservative management of gingival recession: A case report
}

Chaudhary SK, Agrawal H², Dhakal R ${ }^{3}$, Yadav A ${ }^{4}$

${ }^{1}$ Consultant Periodontist, Bijaypur Hospital, Dharan, Nepal.

${ }^{2}$ Consultant Prosthodontist, Bijyapur Hospital, Dharan Nepal

${ }^{3}$ Consultant Periodontist, Bharatpur Hospital, Bharatpur, Nepal

${ }^{4}$ Assistant Professor, Department of Periodontology and Oral Implantology, Nobel Medical College, Biratnagar, Nepal

\begin{abstract}
Smile is the jewel of the face, which not only enhances the beauty of the person but also influences self-confidence. Dental esthetic is composed of white and pink component. The long-term periodontal disease results in the destruction of the pink component leading to gingival recession in some cases, which results in elongated tooth with black triangle and unesthetic smile. When severe destruction is present in the maxillary anterior region surgical reconstruction is unpredictable. This destruction can be masked with a prosthesis like gingival mask after the control of periodontal disease. This case report describes the use of the gingival mask as a conservative treatment modality for recession, achieving optimum esthetics and patient satisfaction.
\end{abstract}

Key words: Gingival mask; gingival recession; gingival veneer

\section{Introduction}

Oingival recession can be a manifestation J of long-standing periodontal disease and can lead to an unesthetic smile with exposed open interdental spaces, elongated clinical crowns and black triangles. ${ }^{1}$ Gingival recession causes an imbalance between pink and white tissue that may result in aesthetic concern and hypersensitivity. ${ }^{2}$ People often seek treatment for such unesthetic smile but due to severe destruction, it may not be possible to regenerate the lost structure or may need complex surgical procedures which are invasive, technique sensitive and expensive, with results that are often unpredictable. ${ }^{3}$ Such procedures may not be accepted by the patient due to invasiveness and unpredictability. So conservative management

Conflict of Interest: No

\section{*Corresponding Author}

Dr. Shashi Kant Chaudhary

Private practice, Bijaypur Hospital Dharan, Nepal.

E-mail: shashi.tooth@gmail.com may be needed and can be done in such cases with a simple prosthesis called gingival mask.

Gingival prostheses have historically been used to replace lost tissue when other methods (e.g., surgery or regenerative procedures) were considered unpredictable or impossible. ${ }^{4} \mathrm{~A}$ gingival mask is defined as a prosthesis worn in the labial aspect of the dental arch, which aims to restore the mucogingival contour and esthetics in areas where periodontal tissues are deficient. ${ }^{5}$ Porcelains, pink auto cure and heat-cured acrylics, composite resins and thermoplastic acrylics, silicone-based soft materials are being used to make gingival mask. Gingival mask is also known as flange prosthesis, gingival veneer, gingival veneer prosthesis, gingival replacement unit, artificial gingiva, gingival slip, and party gums. ${ }^{3}$

This case report describes the conservative technique to mask the gingival recession in a patient with chronic periodontitis, which is noninvasive, stable, economical and esthetically acceptable. 


\section{Case report}

A 40-year female patient reported to the Department of Periodontics and Oral Implantology, B.P Koirala Institute of Health Sciences, Dharan, Nepal with the chief complaint of receding gums, sensitivity and loose teeth. The patient also expressed dissatisfaction with the unaesthetic appearance of the "elongated teeth". On examination, poor oral hygiene with Miller's class IV recession was seen with 14-24, 33-43, grade II mobility with 32-42 (Figure 1). The treatment plan was to restore periodontal health, followed by permanent splinting in the lower anterior, and gingival prosthesis for upper anterior. After explaining all the pros and cons, treatment was started with written consent from the patient.

Phase I therapy was started with supragingival and subgingival scaling with ultrasonic scaler followed with oral hygiene instruction which included the use of desensitizing paste, modified Stillman brushing technique, use of interdental aid (Figure 2). Chlorhexidine 0.2\% as a chemotherapeutic agent was prescribed mouthwash twice daily for 4 weeks. After 1-week Ribbond fibre was used for periodontal splinting for lower anterior teeth from 33-43 to stabilize the anterior (Figure 3). After 4 weeks reevaluation was done.

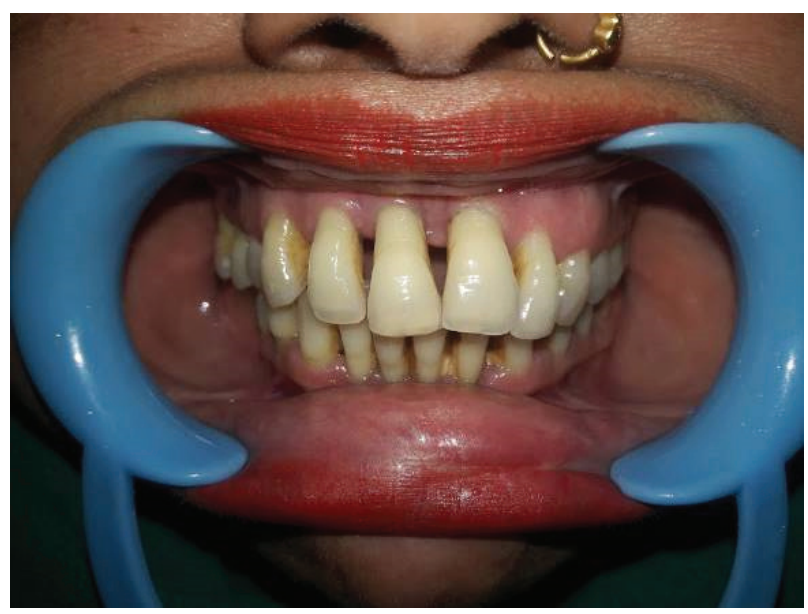

Figure 1: Facial view
For the gingival mask, abuccal approach wasused to create the master impression with complete interproximal detail. Alginate (Tropicalgin, Zhermack, Italy) impression material was used to make a maxillary impression in a perforated stock tray. The impression was then poured with type III dental stone (Kalrock, Kalabhai, India) to fabricate the cast (Figure 4). The extension of the prosthesis was outlined in the cast from the depth of the vestibule to the cementoenamel junction of anterior teeth and a wax-up was done incorporating the surface characterization mimicking healthy gingiva (Figure 5). Flasking of the cast was done followed by dewaxing (Figure 6). Heat cure acrylic resin that is polymethyl methacrylate (Trevlon HI) was packed in the conventional manner. After curing, deflasking was done and the prosthesis was trimmed to remove excess material and then it was tried and adjusted in the patient mouth (Figure 7). The prosthesis was made thin to engage the undercuts. The patient was given instructions to clean it every time after having food and to remove the prosthesis at night to ensure the rest of the gingival tissues. The patient is under maintenance phase, satisfied with the outcome and feels more confident during smiling (Figure 8).

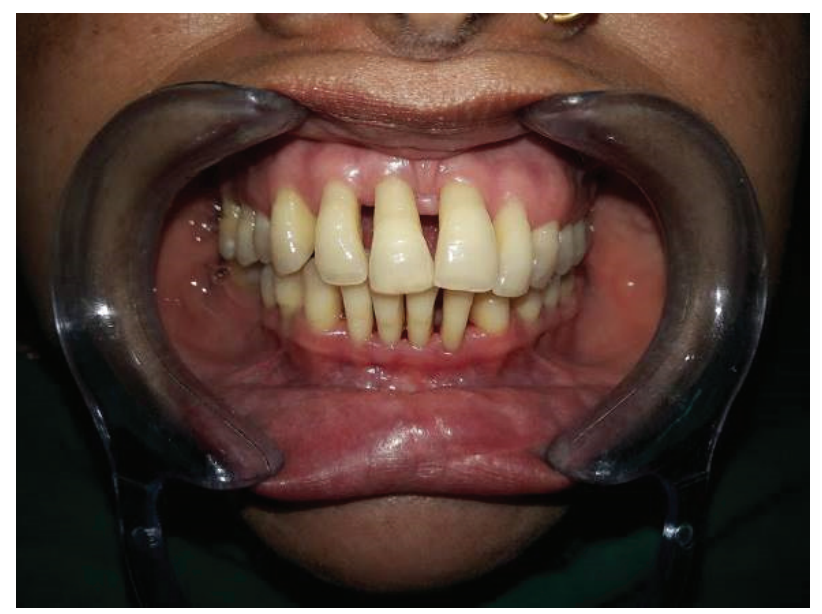

Figure 2: After phase I therapy 


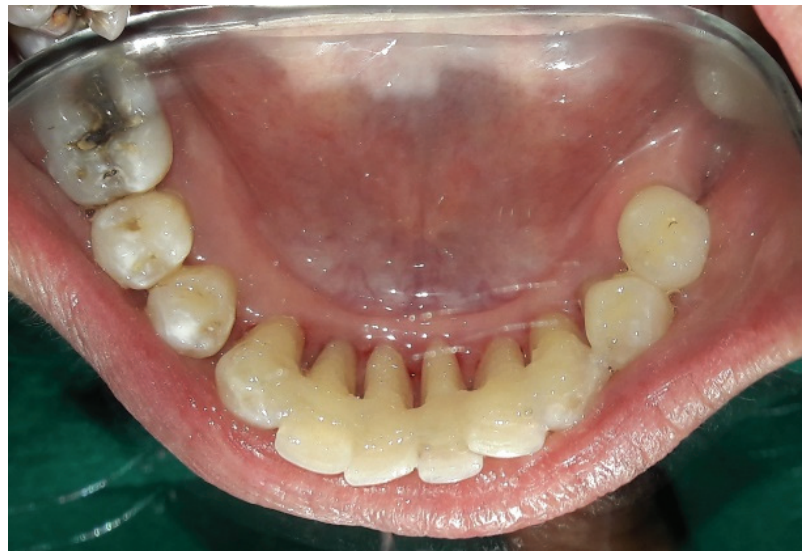

Figure 3: Ribbond fibre splinting

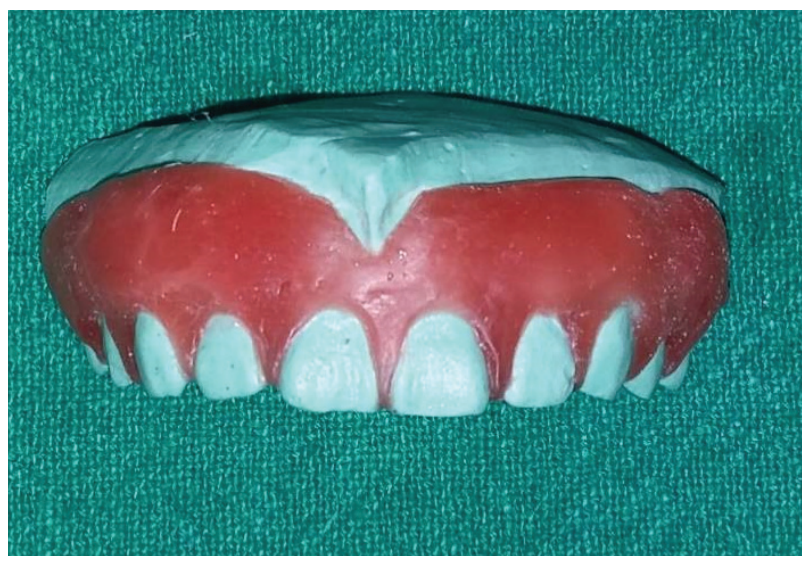

Figure 5: Wax up for gingival mask

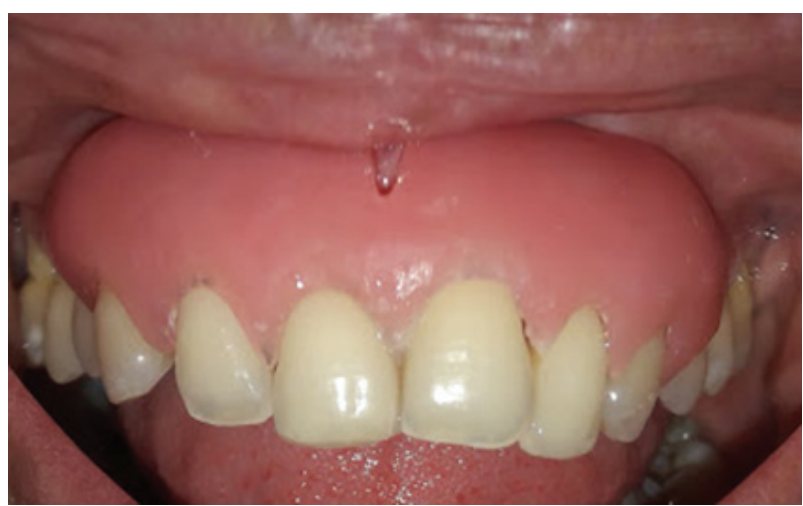

Figure 7: Gingival mask in-situ

\section{Discussion}

Gingival prostheses were first introduced in 1955 by Emslie and were used to mask the unesthetic appearance of gingival recession in a patient who underwent a gingivectomy. ${ }^{6}$ In 1970, L'Estrange et al. reported on several patients that had worn gingival veneers for over 3 years. ${ }^{7}$ Gingival prosthesis takes several forms and various authors have described their uses

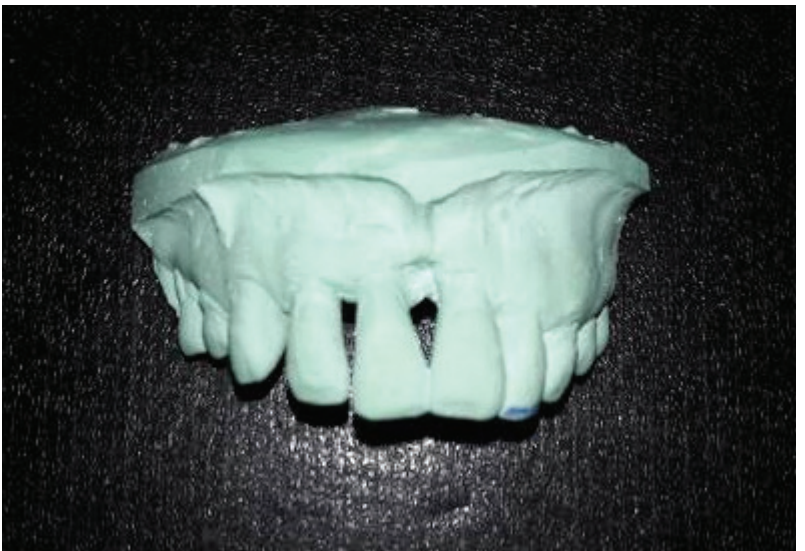

Figure 4: Dental cast

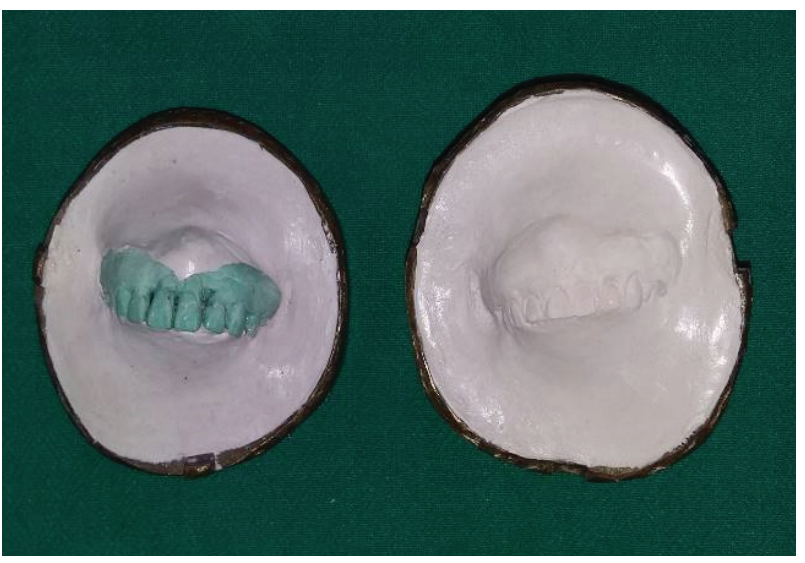

Figure 6: Dewaxing

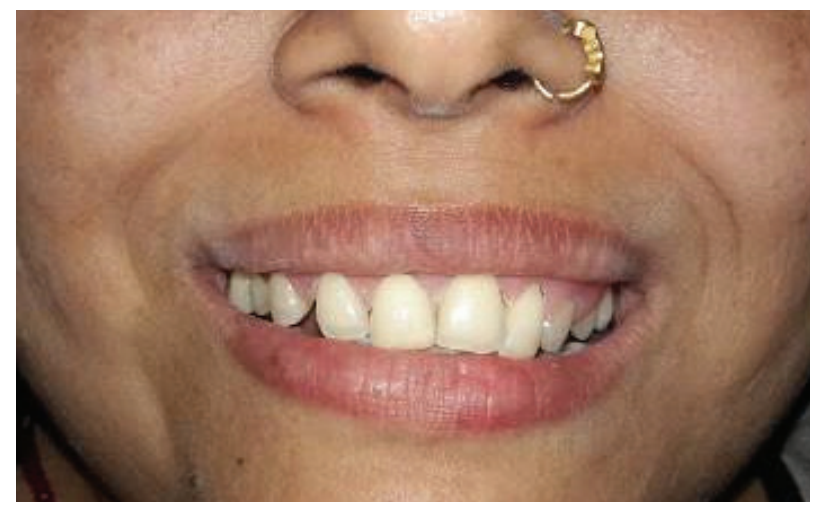

Figure 8: Smile view

and methods of construction. ${ }^{8}$ Currently, there is no predictable surgical method for correcting esthetic deformities that result from generalized attachment loss. In such situations, gingival prosthesis can be used. ${ }^{9}$

The prosthetic option of a gingival mask helps in mimicking the natural appearance of the gingiva in a predictable way, which is cost-effective to the patient. Proper case selection is important 
for a predictable and successful outcome. The gingival mask is contraindicated in patients with poor plaque control, unstable periodontal health, high caries activity, smoking, and known allergy to acrylic or silicone. ${ }^{10}$ The gingival mask is retained mechanically with tiny extensions of the mask material slightly projecting between the roots of the teeth, the natural capillary action created by the saliva and the pressure of the lips against the gingival prosthesis. ${ }^{1}$ This type of prosthesis has limitations. Retention may be difficult, and because of the inherent porosity of the silicone-based material, staining and plaque accumulation may be a problem. Another concern is the possibility of inhalation or ingestion of the prosthesis during function. This type of prosthesis, therefore requires regular maintenance and occasional revision. ${ }^{11}$

\section{Conclusion}

Dental esthetics is composed of white and pink component. So, restoration of the pink component is as important as the white component. In the present case, the gingival prosthesis provides conservative management of lost portion of pink component with enhanced esthetics, reduced hypersensitivity and improved phonetics. Besides this, patient's selfesteem and confidence are also boosted. Such prostheses offer predictable and satisfactory results even with minimum resources and basic expertise.

\section{Acknowledgement}

Dr Shivalal Sharma, Professor and Head, Department Of Periodontology and Oral
Implantology, College of Dental Surgery, BP Koirala Institute of Health Sciences, Dharan, Nepal.

\section{References}

1. Shenava A. Gingival mask: A case report on enhancing smiles. J Oral Res Rev 2014;6:68-70.

2. Chaudhary SK, Shah HK, Goel K, Shrestha S. Laterally positioned flap: a simple and successful technique to cover isolated recession of Miller class-I. J Nepal Soc Periodontol Oral Implantol. 2017;1(2):78-80.

3. Patil S, Prabhu V, Danane NR. Gingival veneer: Mask the unesthetic. J Indian Soc Periodontol 2011;15:284-7.

4. Barzilay I, Irene T. Gingival prostheses: A review. J Can Dent Assoc 2003;69:74-8.

5. Ellis SGS, Sharma P, Harris IR. Case report: aesthetic management of a localized periodontal defect with a gingival veneer prosthesis. Eur J Prosthodont Restor Dent 2000;8(1):23-26.

6. Emslie RD. A case of advanced periodontitis complex. Dental Practitioner 1955;5:432-433.

7. L'Estrange PR, Strahan JD. The wearing of acrylic periodontal veneers. Br Dent $\mathrm{J}$ 1970;128:193-194.

8. Tallents RH. Artificial gingival replacements. Oral Health 1983;73:37-40.

9. Yalamanchili PS, Surapaneni H, Reshmarani AP. Gingival prosthesis: A treatment modality for recession. J Orofac Sci 2013;5:128-130.

10. Shah A. A case report gingival veneer: Noninvasive approach in the management of lost interdental papilla. Int J Dent Case Rep 2012;2:54-58.

11. Hummert TW, Kaiser DA. Block out technique for impression of teeth with increased open gingival embrasures. J Prosthet Dent 1999;82:100-102. 